\title{
Impact of scientific \& technological advances
}

\section{Workshop Report}

Authors:

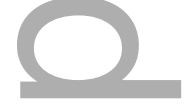

Irina Dragan, DDS, MS, Assistant Professor of Periodontology, Tufts

University School of Dental Medicine, Boston, Massachusetts, USA

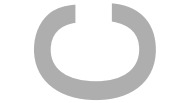

Domenico Dalessandri, DDS, MS, PhD, Lecturer in Orthodontics, University of Brescia, Italy.

Lynn A. Johnson, MS, PhD, Professor and Associate Dean of Faculty Affairs and Institutional Effectiveness (Informatics), University of Michigan School of Dentistry, Ann Arbor, Michigan, USA.

Abigail Tucker, PhD, Professor and Associate Dean Postgraduate research, King's College London Dental Institute, UK.

Damien Walmsley, PhD, MSc, BDS, FDSRCPS, Professor of Restorative Dentistry at the University of Birmingham, UK.

Contact email: irina.dragan@tufts.edu.

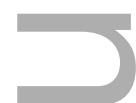

ABSTRACT: Advancements in research and technology are transforming our world. The dental profession is changing too, in light of scientific discoveries that are advancing biological technology - from new biomaterials

This is the author manuscript accepted for publication and has undergone full peer review but has not been through the copyediting, typesetting, pagination and proofreading process, which may lead to differences between this version and the Version of Record. Please cite this article as doi: 10.1111/eje.12342

This article is protected by copyright. All rights reserved 
to unravelling the genetic makeup of the human being. As health professionals we embrace a model of continuous quality improvement and lifelong learning. Our pedagogical approach to incorporating the plethora of scientific technological advancements calls for us to shift our paradigm from emphasis on skill acquisition to knowledge application. The 2017

ADEE/ADEA workshop provided a forum to explore and discuss strategies to ensure faculty, students and, ultimately, patients are best positioned to exploit the opportunities that arise from integrating new technological advances and research outcomes. Participants discussed methods of incorporating the impact of new technologies and research findings into the education of our dental students. This report serves as a signpost of the way forward and how to promote incorporation of research and technology advances and lifelong learning into the dental education curriculum.

KEYWORDS: technology advances, scientific discoveries, evidence based dental practice, lifelong learning.

\section{INTRODUCTION}

The Global Congress on Dental Education in 2008 stated that "dental students, educators or patients are like chameleons adapting to the ever-changing landscape". ${ }^{1}$ This is still true for areas of technologies (preclinical, clinical and classroom settings) and scientific discoveries pertinent to dental education. The previous discussion to this review, followed two strands, the uptake of technology and the introduction of new scientific findings into the curriculum. The technology component covers the advances in this popular educational area with a focus on how to deliver educational materials and the growth of haptic learning. The second part reviews how the latest scientific advances in medicine and dentistry are being embedded into dental education. This workshop included the role of critical analysis of the scientific literature leading to the use of best scientific evidence for our patient care.

Technology has changed the delivery of educational material, whilst research findings are influencing what we teach our students about dentistry. There is an ever-increasing amount of information and our students must be "smart thinkers" where they can critically analyze the literature and apply it to their everyday practice. Scientific advancements are

This article is protected by copyright. All rights reserved 
changing how medicine is delivered to the patient and this in turn is changing our concepts of educating our students. This narrative comes out of discussions during the ADEE/ADEA London 2017 Conference and attempts to review the signposts in those areas where the most important advances are taking place, but should not be seen as an exhaustive review of all the different aspects where science and technology are influencing the curriculum.

In order to meet the expectations of the participants, a preconference survey was designed and distributed to the registered participants of the workshop. The workshop participants were representatives of institutions from around the world: Bulgaria, Canada, China, Egypt, France, Finland, Greece, Hungary, India, Ireland, Israel, Italy, Japan, Kuwait, Lithuania, Norway, The Netherlands, Pakistan, Romania, Saudi Arabia, Slovenia, Spain, Sweden, Switzerland, Turkey, United Kingdom, and United States of America. The collected data identified the preferred focus of the participants was: best practices $(n=8 ; 22 \%)$ and facilitating a discussion with the experts $(n=18 ; 50 \%)$. The aim of this workshop was to provide a forum to explore and discuss strategies to ensure faculty, students and, ultimately, patients are best positioned to exploit the opportunities that arise from recent scientific discoveries and integration of technologies. Further, we aimed to establish best practices for incorporating the impact of new research findings and technological advances into the education of our dental students.

In Summary, the willingness and ability of our dental students and educators to adapt to the unpredictable future will always ensure that our patients receive the best possible care.

\section{TECHNOLOGICAL ADVANCES}

Education is certainly one of the fields that greatly benefited from technology, in

both the teaching and the learning aspects. ${ }^{2,3}$ The use of technology in dental

education has paved the way for innovative teaching methods and an increase in student engagement. ${ }^{4}$ Our digital native students possess the necessary skills to compete and strive in the twenty-first century, while integrating efficiently technologies into their educational process. ${ }^{5}$ The use of new technologies in dental schools has been incorporated for years in various capacities: in the classroom, clinical, preclinical and institutional organization. ${ }^{6-11}$ The Commission on Dental Accreditation recommends the "application of technology in dental education programs to improve patient care, and to revolutionize all 
aspects of the curriculum, from didactic courses to clinical instruction". In 2003, the results of a national survey revealed the use of information technology at U.S. dental schools, highlighting the uncertainty in the speed and the level of integration of new technologies in all capacities of an academic environment. ${ }^{2}$ In 2008, a consensus paper published by international experts in dental education, reported that technologies can assist in acquisition of knowledge and in attaining competence in clinical skills. ${ }^{1}$ Recently published literature provides answers to "a series of myths that exist about the use of technology in education" and creates a framework to the available technologies existing for patient-care. ${ }^{3}$

Based on our literature review, the main technologies currently used in the dental education can be divided into didactic, preclinical and clinical settings. In the context of this manuscript "didactic" appears to mean technology that is used with students "in the classroom". "In the classroom" strategies take a number of forms many of which are mentioned in the Scientific Discoveries section.

For the "in classroom" setting, the following technologies were reported:

laptops/tablets; exam software; lecture capture; simulcasting and student response systems. Simulation models, haptic technology and virtual patients are in use in preclinical settings. The impact of new technologies is not restricted to the educational process. All specialties of the dental field benefit from the technological advancements. 3D printing, digital treatment planning, lasers are only a few technologies that are being used across disciplines.

Electronic health records (EHRs) play an increasingly key role in the practice of dentistry and they have been integrated successfully in the dental curriculum.

Most recently, tele-health technologies tailored to dental practice have gained popularity and more studies are evaluating their benefits.

\section{Workshop results of the emerging technologies in dental education}


The Workshop participants were asked to describe the most important technologies that are most likely going to be used in dental education and patient care in 2027. They described the following technologies that are emerging as technologies that will be considered standard learning technologies by 2017.

Preclinical Education: augmented reality, haptic technology, virtual reality, Japanese robot patient simulator, integrated TEL system, hyperlinked 2D/3D, 3D printing, faculty evaluation, video and audio with analysis for self and external evaluation, eportfolio, VR complements mannequins, 3D printing simulates tissues, collaborative learning technologies, video for teaching communications.

- "In the classroom" Learning: podcasts and webinars, software for curriculum management/mapping, assessment, delivery strategies, virtual reality, interactive e Learning, case-based, social media as advising and motivation tool, gaming, cloud LMS, student evaluation of faculty teaching, cross country and institution teaching, flexibility in lecture, flipped classroom, daily quizzes, online learning with embedded quizzes.

- Tele-health: professional versus students, variety of techniques, most untested, behavioural approaches and skills, data used for decision support, access, cost, follow-up care, second opinion, speciality care, faculty evaluation of teaching, team teaching (horizontal \& vertical), interdisciplinary experiences including geographical, record consultations and add to cloud electron health records (EHR), smart watch for notifications, consultations, diagnosis, triage, combine with mobile clinics, cloud EHR and advanced data collection.

- Patient Care: videos of treatment and analysis to provide feedback to student, artificial intelligence that learns about student (analytics), complex scenarios, 3D printing, CBCT, genetic sequencing, personalized medicine, big data for decision support, imaging, scanning, e-assisted surgical tools, faculty evaluation, team (horizontal and vertical), patient perspective, e-portfolio, community-based education, voice operated EHRs, integrated EHRs, CAD/CAM, inter-professional collaborations.

Concern: Recognizing the uncertainty of predicting the future, the greatest concern of the participants was not about students or technology, but was focused on faculty. How 
will educators adapt to these new technologies and "prepare students for a future we cannot predict"?

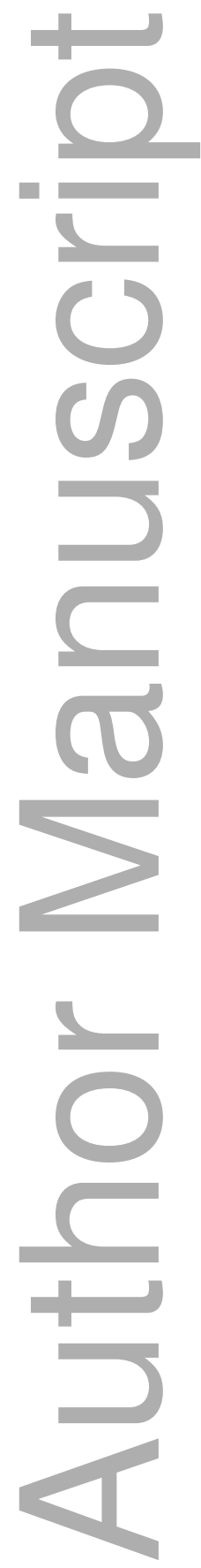

This article is protected by copyright. All rights reserved 


\section{SCIENTIFIC DISCOVERIES}

In this 21 st century several important scientific discoveries have emerged along with the concept of Personalized (or Precision) Medicine, possible through the availability of unique comprehensive individualized datasets (genetic, genomic,

clinical and environmental) that are paving the way for tailor-made treatment plans.

An analysis of recently published articles highlights some promising areas where key scientific discoveries have emerged, driven by advances in next generating sequencing techniques, transgenic mouse models, in vivo imaging, and biomaterials/nanotechnology, allowing for significant advances in stem cell technology, salivaomics, the microbiome, bioprinting and nanoengineered for tissue repair and regeneration. ${ }^{12}$ To enhance the delivery of personalized and precision dental care and to fill the translational gap for research findings to be incorporated into practice by general practitioners a strong collaboration between researchers, clinicians, and educators is needed. Discovery-driven, translational and applied research should be conducted by researchers together with clinicians, and dental educators have the responsibility to prepare their students to be that inquisitive dentists able to discern which are the most promising scientific discoveries and to participate to the process of their translation into everyday practice.

The following are some of the reasons highlighted in the literature that explain the translational gap: most research is conducted in highly controlled environments, such as academic settings, and represents only a small percentage of what actually occurs in practice; the lack of knowledge transfer of the safety, efficacy, and effectiveness of an intervention to practitioners; absence of a formal process for the adoption of new technologies, that is currently dependent on dissemination through dental meetings, research publications, continued education programs, and testimonials. The effectiveness of new knowledge (innovation) transfer into everyday practice is influenced by internal factors, mainly depending on the type of knowledge on offer, and by external factors, such as personal inclination to adopt change, financial viability, the culture of the practice and perceived relevance of the existing research to this specific clinical practice. 
Based on a literature review, several approaches could be used in dental education to teach students the skills to question clinical decisions, to search for evidence, to appraise it, to implement it and to evaluate it. ${ }^{13}$ These include: Problem Based Learning (PBL), intentional learning, reflection, motivation and, generally speaking, and critical thinking techniques. Furthermore, students could be involved in "academic detailing" projects allowing them to visit practitioner's offices to provide evidence-based information about patient care topics and to understand the need for keeping up with the current literature throughout professional life. Finally, Practice Based Research Networks (PBRN) could be created under the direction of one or more academic health science centers, involving community practitioners in conducting clinical studies, evaluating treatments that are standard of care in a real world setting.

\section{Workshop results of the best science practices in dental education}

The Workshop participants were asked to pick the most important scientific discoveries that would be important for dentistry and to discuss how such information could be introduced to students. In particular, the participants were asked to discuss how we can create critical thinkers to be sophisticated consumers of research.

[same suggestion as in the previous section.]

- New ideas - what are the most important areas of new scientific discoveries: early diagnosis and monitoring, nanomedicine, informatics, saliva as a diagnostic; ecology, microbiome and the biofilm: understanding interactions with our microbiome for early diagnosis; regenerative dentistry (soft \& hard tissues); bioactive materials: enhancing the tooth's innate ability to repair

- Way forward: how do we introduce these new discoveries to our students and create critical thinkers: change assessment methods (embedding critical thinking in assessment); giving the students robust methodology for evaluation of evidence (prepare faculties - Socratic approach); clinical treatment planning \& case discussion; inter year, inter- \& intra- professional (peer to peer support \& librarians); personalize (make your own soup) innovative creative methods (gamification, social media), stimulate passion. 
Example of best practice from a group: getting students to carry out systematic reviews of the literature and learn how to critical assess what they read. Importance of learning how to analyse bias; importance of being exposed to both good and bad systematic reviews in order to learn the pros and cons of meta-analysis.

Key message: Evidence based dentistry needs to be clinically contextualised and that research and research methodology should be integrated into the curriculum and wider into the community.
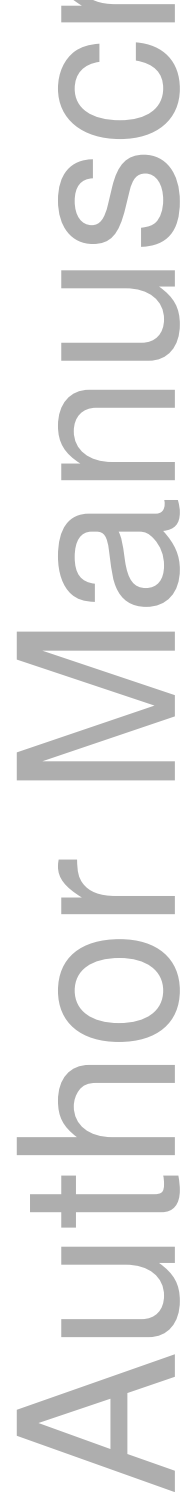


\section{REFERENCES}

1. Mattheos N, Stefanovic N, Apse P, et al. Potential of Information Technology in Dental Education. Eur J Dent Educ. 2008 Feb;12 Suppl 1:85-92.

2. Wrzosek M, Warner G, Donoff RB, Howell TH, Karimbux N. A Survey of Information Technology Management at U.S. Dental Schools. J Dent Educ. 2003 Oct;67(10):1095-106.

3. Brownstein SA, Murad A, Hunt RJ. Implementation of New Technologies In U.S. Dental School Curricula.J Dent Educ. 2015 Mar;79(3):259-64.

4. Irving M, Stewart R, Spallek H, Blinkhorn A. Using Teledentistry In Clinical Practice, an Enabler to Improve Access to Oral Health Care: A Qualitative Systematic ReviewJ Telemed Telecare. Accepted 2017 Jan 16.

5.Spallek H, Von Bergmann H. Should Laptops Be Allowed in The Classroom? Two Viewpoints: Viewpoint 1: Laptops in Classrooms Facilitate Curricular Advancement and Promote Student Learning and Viewpoint 2: Deconstructing and Rethinking the Use of Laptops in the Classroom. J Dent Educ. 2014 Dec;78(12):1580-8;

6. Kramer GA, Neumann LM. Confirming The Validity of Part II of the National Board Dental Examinations: a Practice Analysis. J Dent Educ. 2003 Dec;67(12):1286-98;

7. Koo S, Kim A, Donoff RB, Karimbux NY. An Initial Assessment of Haptics in Preclinical Operative Dentistry Training. J Investig Clin Dent. 2015 Feb;6(1):69-76.

8.Cederberg RA, Bentley DA, Halpin R, Valenza JA. Use of Virtual Patients In Dental Education: a Survey Of U.S. and Canadian Dental Schools. J Dent Educ. 2012 Oct; 76 (10):1358-64.

9.Lie T, Hoff I, Gjerdet NR. Computerized Evaluation of the Effectiveness of Subgingival Scaling in Jaw Models. An Introduction to the Program Developed at the School of Dentistry, University of Bergen. J Clin Periodontol. 1987 Mar;14(3):149-55.

10.Glassman P, Harrington M, Mertz E, Namakian M. The Virtual Dental Home: Implications for Policy and Strategy. J Calif Dent Assoc. 2012 Jul;40(7):605-11.

This article is protected by copyright. All rights reserved 
11. Daniel SJ, Wu L, Kumar S. Teledentistry: A Systematic Review of Clinical Outcomes, Utilization and Costs. J Dent Hyg. 2013 Dec;87(6):345-52.

12. Hopper L, Morris L, Tickle M. How primary care dentists perceive and are influenced by research. Commun Dent Oral Epidemiol 2011; 39: 97-104.

13. Hendricson WD, Rugh JD, Hatch JP, Stark DP, Deahl T, Wallmann ER. Validation of an instrument to assess evidence-based practice knowledge, attitudes, access, and confidence in the dental environment. J Dent Educ 2011 75:131-144.

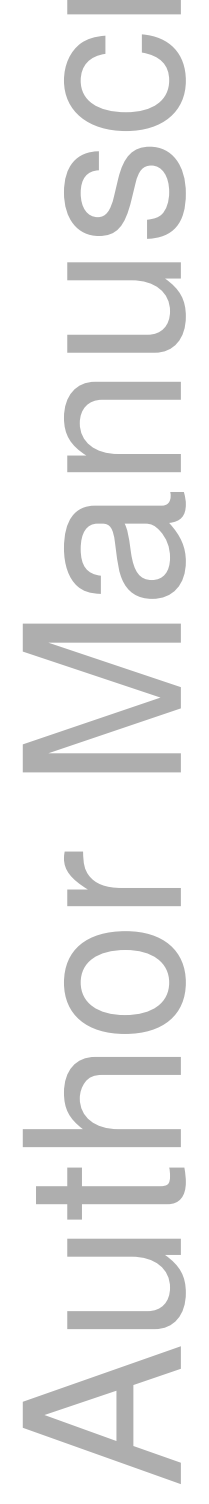

